\title{
The Complete Mitochondrial Genome of Dendronephthya gigantea (Anthozoa: Octocorallia: Nephtheidae)
}

\author{
Eunji Park, Boa Kim and Yong-Jin Won* \\ Division of EcoScience, Ewha Womans University, Seoul 120-750, Korea
}

\begin{abstract}
We sequenced the whole mitochondrial genome of Dendronephthya gigantea (Anthozoa: Octocorallia: Nephteidae), the first mitochondrial genome sequence report in the Family Nephtheidae. The mitochondrial genome of $D$. gigantea was 18,842 bp in length, and contained 14 protein coding genes (atp6 and 8, coxl-3, cytb, ndl6 and $4 L$, and $m s h 1$ ), two ribosomal RNAs, and only one transfer RNA. The gene content and gene order is identical to other octocorals sequenced to date. The portion of the noncoding regions is slightly larger than the other octocorals (5.08\% compared to average 3.98\%). We expect that the information of gene content, gene order, codon usage, noncoding region and protein coding gene sequence could be used in the further analysis of anthozoan phylogeny.
\end{abstract}

Keywords: Octocorallia, Nephtheidae, mitochondrial genome, Korea

\section{INTRODUCTION}

The subclass Octocorallia (Cnidaria: Anthozoa) comprises approximately 3,000 extant species of soft corals, sea pens, gorgonians and blue corals (Daly et al., 2007). To elucidate the evolutionary relationships within octocorals, much research has been conducted using $18 \mathrm{~S}$ rRNA, cox $1, n d 2$ or $m s h 1$ genes (Berntson et al., 1999, McFadden et al., 2006). However, because of the lack of enough amount of nucleotide substitution due to slow evolution of mitochondrial and nuclear ribosomal genes, a clear phylogenetic relationship has remained unsolved (Hellberg, 2006).

Mitochondrial genomes (mitogenomes) have been used for phylogenetic studies in diverse animal groups (Brugler and France, 2007, Sinniger et al., 2007, Wang and Lavrov, 2007). Not only protein coding genes, but also gene order, gene content, and non-coding regions can be used in phylogenetic analyses (Gissi et al., 2008). Currently, only six octocoral mitogenomes have been sequenced, in contrast with 27 hexacoral mitochondrial genome sequences available on GenBank. For the phylogenetic analysis of octocorals, more mitochondrial genome information is needed. In a previous study we constructed anthozoan phylogeny and estimated divergence time between hexacorals and octocorals using 13 protein coding mitochondrial genes including D. gigantea (Kim et al., 2008) reported in this paper. The

*To whom correspondence should be addressed

Tel: 82-2-3277-4471, Fax: 82-2-3277-4514

E-mail: won@ewha.ac.kr result showed that the first splitting event among four octocoral species had occurred around 50-79 million years ago (Ma). In contrast, 16 different hexacoral species showed relatively long history of divergence ( $>240 \mathrm{Ma}$ ). The discrepancy mainly arose from the very limited taxon sampling of the octocorals compared to the hexacorals (Kim et al., 2008). These results provided insights into the anthozoan evolution and also highlighted the need and importance of more extensive taxon sampling, particularly in octocorals, for better understanding of phylogenetic relationships among anthozoans. Here, we determined and described the complete mitochondrial genome sequence of $D$. gigantea, the first report from the Family Nephtheidae.

\section{MATERIALS AND METHODS}

\section{Sample collection and DNA extraction}

D. gigantea specimen was collected at a depth of $20 \mathrm{~m}$ on the cliff of Munseom Island, south of the Jejudo Island, Korea in 2005. Several $2 \mathrm{~cm}$ long branches were dissected and stored in $95 \%$ ethanol at $-50^{\circ} \mathrm{C}$ until use. Total genomic DNA was extracted using a DNeasy Blood and Tissue Kit (Qiagen Inc., Valencia, CA, USA), following the manufacturer's protocol.

\section{PCR amplification and sequencing}

Thirty-one primer pairs were newly designed to amplify the complete octocoral mitochondrial genome (Table 1), selecting 
Table 1. The 31 primer pairs used to amplify the whole mitochondrial genome of Dendronephthya gigantea

\begin{tabular}{|c|c|c|c|}
\hline Primer & Sequence & Primer & Sequence \\
\hline $1 \mathrm{~F}$ & ATGAACAAATATCTTACACG & $1 \mathrm{R}$ & ATAARTGCTGRAATAAAAT \\
\hline $2 \mathrm{~F}$ & CAATGTTATTGACAGATAGA & $2 \mathrm{R}$ & GCTAAACCCAAGAAATG \\
\hline $4 \mathrm{~F}$ & CTGGTCGAAGATGCGTAGTA & $4 \mathrm{R}$ & TGTGCTAACACTGGGTTAGA \\
\hline $5 F$ & TGGATTAAGTCAGGTGTC & $5 R$ & ATAGCTAATCATTTGAGC \\
\hline $6 \mathrm{~F}$ & GTACTAGCTGATATTAATGT & $6 \mathrm{R}$ & YACTGCATCTAAACCTATCA \\
\hline $8 \mathrm{~F}$ & ATATTITAAGAGACGTTAAT & $8 \mathrm{R}$ & СТСTACTGGATTAGCCССTA \\
\hline $9 F$ & ATCCTTTAGTAACTCСTG & $9 R$ & TTGGCCAGAAGGCACCTA \\
\hline $10 \mathrm{~F}$ & TGCTAGTITGGTGCTACTAG & $10 \mathrm{R}$ & TCGGCAGCTGCGACAGTTAA \\
\hline $11 \mathrm{~F}$ & AGGTATTATTCTTAATAGAA & $11 R$ & TTACAACTAGGAGARTAAAC \\
\hline $12 \mathrm{~F}$ & YTRCTTCAAATGGGGTTTCC & $12 \mathrm{R}$ & AGAATTGTAACACTCGGG \\
\hline $13 \mathrm{~F}$ & CTTAGTAAAATATTTCAAAG & $13 R$ & TGTATCTTGAAAYACAATAT \\
\hline $14 \mathrm{~F}$ & TGGGCYGAACARAYTTCAAA & $14 \mathrm{R}$ & TAARCTGTTATAATTAGCTA \\
\hline $16 \mathrm{~F}$ & CTATITTAGGYTGGAAGAGA & $16 \mathrm{R}$ & ACTTCCTGTITGTCTAAGTT \\
\hline $17 \mathrm{~F}$ & ACTGGTGTAGTAAGACTA & $17 R$ & TTTCСTCTTGAGACAGTA \\
\hline $18 \mathrm{~F}$ & TGACCGTGATAATGTAGCAC & $18 \mathrm{R}$ & GGCACCTTATTAATCCCWAA \\
\hline $19 F$ & TGGTGACACAGCTCGGTT & $19 R$ & GCACGATAGATAATAGCGCA \\
\hline $20 \mathrm{~F}$ & ATTRTTATTTAAAGTATCTG & $20 \mathrm{R}$ & ATATTTGTTATTACTAAAGG \\
\hline $21 \mathrm{~F}$ & GTTITTAACTAARTGGTATR & $21 R$ & TCCCAACCRATAAATARTTG \\
\hline $22 \mathrm{~F}$ & ATTCTACAAGTTATATGAGA & $22 R$ & GCATGAATRATTGAGCCTGC \\
\hline $23 \mathrm{~F}$ & AGTTTATATCAYYTACTAAC & $23 R$ & TATCATTAATGCATAATTAA \\
\hline $24 \mathrm{~F}$ & ATGCCTGGGAGTTTAATC & $24 \mathrm{R}$ & AGAAGAAATAATAAGCAGCT \\
\hline $25 \mathrm{~F}$ & TITGAAAGTATATTAATACC & $25 \mathrm{R}$ & GTACTAGTWGAAAAAGCAGC \\
\hline $26 \mathrm{~F}$ & ATGGTRTTTACTTTAGCTAA & $26 \mathrm{R}$ & GCTGCTAGTTGGTATTGGCA \\
\hline $27 \mathrm{~F}$ & CTAAGARCCCCACCARTAAA & $27 R$ & TATCACCСTTATCATYTAGT \\
\hline $28 \mathrm{~F}$ & TGAAAATATARTACTGAGCC & $28 \mathrm{R}$ & TCWACAGCTAAYAAGGGAAC \\
\hline $29 F$ & GTAAATACRTAGGGAAATAG & $29 R$ & CATTAGSTATTAAAATGGAT \\
\hline $30 F$ & GAGTGATTAGCGCCACATAA & $30 \mathrm{R}$ & GGAGCCTATATCCTTGRGAT \\
\hline
\end{tabular}

conserved sites among four octocorallian genome sequences available on GenBank (accession IDs: DQ640649, DQ640646, AF064823, and AF063191). Each primer pair was designed to amplify an approximate 700-bp segment, and each amplicon was overlapped by about $70 \mathrm{bp}$ with both $5^{\prime}$ and $3^{\prime}$ adjacent segments. PCR reactions were conducted using the following conditions: initial denaturation step at $94^{\circ} \mathrm{C}$ for $1_{-}$ min, 35_cycles at $92^{\circ} \mathrm{C}$ for $40 \mathrm{sec}, 50^{\circ} \mathrm{C}$ for $1 \mathrm{~min}, 72^{\circ} \mathrm{C}$ for $1 \mathrm{~min}$, followed by a final extension step at $72^{\circ} \mathrm{C}$ for $7 \mathrm{~min}$. PCR products were purified with a LaboPass PCR purification kit (Cosmo Genetech Inc. Seoul, Korea), and sequenced using an ABI3730XL instrument (50-cm capillary).

\section{Gene annotation and sequence analysis}

To construct a complete mitogenome contig, 31 sequences were aligned and assembled using AlignIR ( $\mathrm{LiCoR})$. Protein coding genes and rRNA genes were identified with a blast search based on sequence similarity and confirmed by ORF Finder (NCBI). Transfer RNA genes were searched with the tRNA scan-SE program (Lowe and Eddy, 1997), and codon usage was calculated using DnaSP 5.0 (Librado and Rozas,
2009).

\section{RESULTS}

\section{Genome composition and gene order}

The mitochondrial genome of $D$. gigantea consisted of 18,842 bp in length (GenBank accession ID: FJ372991, Fig. 1) and contained 14 protein coding genes (atp6 and 8, cox 1 3 , cytb, ndl-6 and $4 L$, and $m s h l$ ), two rRNA genes (large and small subunit ribosomal RNA), and one tRNA gene (for methionine), which was identical to the typical octocoral species reported so far in terms of genome composition (McFadden et al., 2010). Additionally, the gene order was identical to other octocorals except for the deep-sea bamboo coral species of the Family Isididae (Brugler and France, 2008).

\section{Protein coding genes and codon usage}

In general, metazoan mitochondrial genomes consist of 13 protein coding genes (atp6 and 8, coxl-3, cytb ndl-6 and 4L), 
however, the octocoral mitochondrial genome contained an additional bacterial mutS homolog $m s h l$ gene, which has not been documented in other metazoans, even in the sponge and hexacoral mitochondrial genomes (Pont-Kingdon et al., 1998). Among the 14 protein coding genes, ten genes (coxl, $n d 1, c y t b, n d 6, n d 4, n d 4 L, m s h 1, n d 2, n d 5$, and $n d 4)$ were encoded in the heavy strand and the remaining four genes

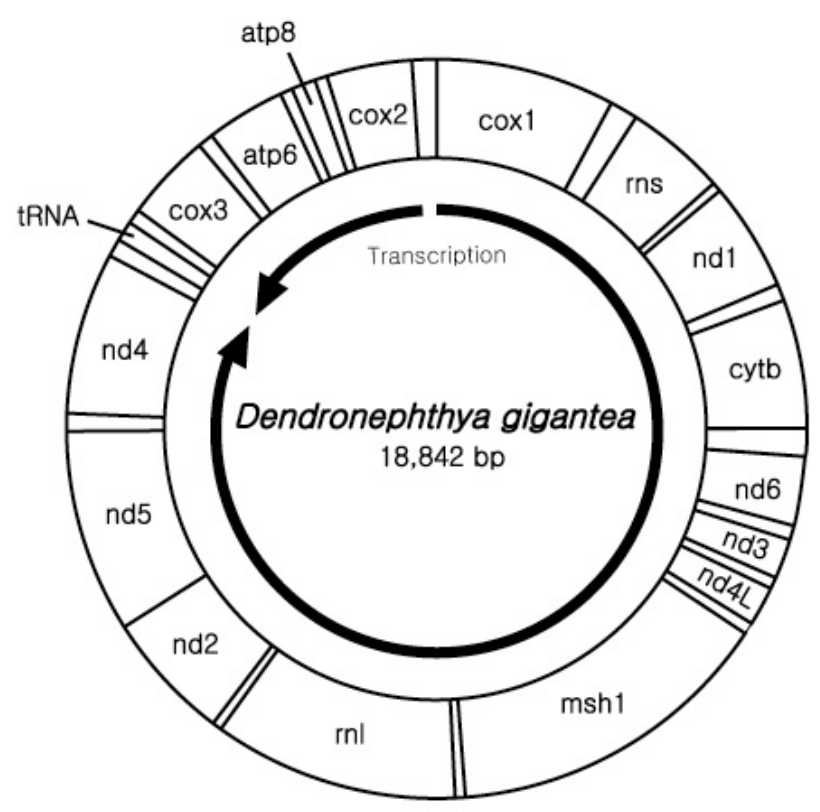

Fig. 1. Circular map of Dendronephthya gigantea mitochondrial genome. (cox3, apt6, atp8, and cox2) were encoded in the light strand (Table 2). All genes are inferred to start with an ATG codon and terminated with a TGA or TAA stop codon except coxl, which ended with an ATTT sequence, and is considered to make a TAA stop codon by adding multiple adenines to the $3^{\prime}$ end of the mRNA strand (Anderson et al., 1981). According to the codon usage program, UUA for Leu (RSCU 3.30) and AGA for Arg (RSCU 2.65) were highly preferred. In contrast, UCA for Trp (RSCU 0.07) and CUC for Leu RSCU 0.15) were highly avoided (Table 3 ).

\section{Ribosomal and transfer RNA genes}

The $D$. gigantea mitochondrial genome encoded $12 \mathrm{~S}$ and 16S rRNA genes of 923 and 2,171 bp, respectively. The small subunit ribosomal RNA was located between the coxl and $n d l$ genes, and the large subunit ribosomal RNA was found between the $m s h 1$ and $n d 2$ genes. Compared to typical metazoan mitochondrial genomes, which have 22 tRNAs (Gissi et al., 2008), all six octocorals sequenced to date have only one type of $t R N A^{M e t}$. The tRNA for methionine of D. gigantea which is $71 \mathrm{bp}$ in length, was located between $n d 4$ and $\operatorname{cox} 3$ (Fig. 2).

\section{Non-coding region}

Non-coding intergenic regions occupied 5.08\% (957 bp/ $18,842 \mathrm{bp}$ ) of the total length of the $D$. gigantea mitogenome and showed a large proportion of noncoding DNA/total DNA compared to the other five octocoral mitogenomes (average 3.96\%, McFadden et al., 2010). All genes were separated by non-coding regions with a range of $4 \mathrm{bp}$ to

Table 2. Organization of the Dendronephthya gigantea mitochondrial genome

\begin{tabular}{|c|c|c|c|c|c|c|c|c|}
\hline \multirow{2}{*}{ Gene } & \multicolumn{2}{|c|}{ Position } & \multicolumn{2}{|c|}{ Length } & \multicolumn{2}{|c|}{ Codon } & \multirow{2}{*}{ Strand } & \multirow{2}{*}{$\begin{array}{l}\text { Intergenic } \\
\text { nucleotides }\end{array}$} \\
\hline & Start & Stop & Nucleotides & Amino acids & Start & Stop & & \\
\hline $\operatorname{cox} 1$ & 1 & 1597 & 1597 & 533 & ATG & $T(A A)^{a}$ & + & 151 \\
\hline rns & 1749 & 2671 & 923 & & & & + & 4 \\
\hline nd1 & 2676 & 3647 & 972 & 324 & ATG & TAG & + & 82 \\
\hline cytb & 3730 & 4866 & 1137 & 379 & ATG & TAG & + & 199 \\
\hline$n d 6$ & 5066 & 5623 & 558 & 186 & ATG & TAG & + & 43 \\
\hline$n d 3$ & 5667 & 6020 & 354 & 118 & ATG & TAG & + & 19 \\
\hline$n d 4 L$ & 6040 & 6333 & 294 & 98 & ATG & TAA & + & 30 \\
\hline msh1 & 6347 & 9286 & 2940 & 980 & ATG & TAA & + & 9 \\
\hline$r n l$ & 9296 & 11466 & 2171 & & & & + & 4 \\
\hline$n d 2$ & 11471 & 12628 & 1158 & 386 & ATG & TAG & + & $-13^{b}$ \\
\hline$n d 5$ & 12616 & 14433 & 1818 & 606 & ATG & TAG & + & 84 \\
\hline$n d 4$ & 14518 & 15966 & 1449 & 483 & ATG & TAA & + & 72 \\
\hline$t R N A^{M e t}$ & 16039 & 16109 & 71 & & & & - & 39 \\
\hline $\operatorname{cox} 3$ & 16149 & 16934 & 786 & 262 & ATG & TAG & - & 64 \\
\hline atp6 & 16999 & 17706 & 708 & 236 & ATG & TAA & - & 24 \\
\hline atp8 & 17731 & 17946 & 216 & 72 & ATG & TAG & - & 22 \\
\hline $\cos 2$ & 17969 & 18730 & 762 & 254 & ATG & TAG & - & 111 \\
\hline
\end{tabular}

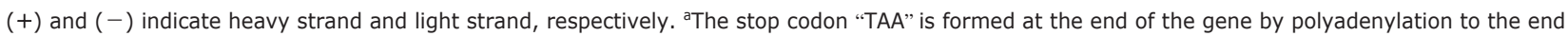
of cox1 mRNA which ends with "T". 'Negative value indicates overlapping region of two adjacent genes. 
Table 3. Codon Usage

\begin{tabular}{|c|c|c|c|c|c|c|c|c|c|c|c|}
\hline $\begin{array}{l}\text { Amino } \\
\text { acids }\end{array}$ & Codon & No. & RSCU & $\begin{array}{c}\text { Amino } \\
\text { acids }\end{array}$ & Codon & No. & RSCU & $\begin{array}{l}\text { Amino } \\
\text { acids }\end{array}$ & Codon & No. & RSCU \\
\hline \multirow[t]{2}{*}{ Phe } & UUU & 221 & 1.51 & Thr & $\mathrm{ACU}$ & 113 & 1.82 & Cys & UGU & 51 & 1.65 \\
\hline & UUC & 72 & 0.49 & & ACC & 33 & 0.53 & & UGC & 11 & 0.35 \\
\hline \multirow[t]{6}{*}{ Leu } & UUA & 405 & 3.30 & & ACA & 85 & 1.37 & Trp & UGA & 3 & 0.07 \\
\hline & UUG & 82 & 0.67 & & ACG & 18 & 0.29 & & UGG & 87 & 1.93 \\
\hline & CUU & 94 & 0.77 & Ala & GCU & 161 & 1.87 & Arg & CGU & 29 & 1.20 \\
\hline & CUC & 18 & 0.15 & & GCC & 68 & 0.79 & & CGC & 8 & 0.33 \\
\hline & CUA & 109 & 0.89 & & GCA & 94 & 1.09 & & CGA & 18 & 0.74 \\
\hline & CUG & 29 & 0.24 & & GCG & 22 & 0.26 & & CGG & 11 & 0.46 \\
\hline \multirow[t]{3}{*}{ Ile } & AUU & 240 & 1.41 & Tyr & UAU & 192 & 1.63 & Ser & AGU & 97 & 1.49 \\
\hline & AUC & 51 & 0.30 & & UAC & 43 & 0.37 & & AGC & 52 & 0.80 \\
\hline & AUA & 218 & 1.28 & Stop & UAA & 4 & 0.62 & Arg & AGA & 64 & 2.65 \\
\hline Met & AUG & 146 & 1.00 & & UAG & 9 & 1.38 & & AGG & 15 & 0.62 \\
\hline \multirow[t]{4}{*}{ Val } & GUU & 130 & 1.56 & $\mathrm{His}$ & CAU & 76 & 1.42 & Gly & GGU & 93 & 1.10 \\
\hline & GUC & 32 & 0.38 & & CAC & 31 & 0.58 & & GGC & 48 & 0.57 \\
\hline & GUA & 103 & 1.23 & Gln & CAA & 108 & 1.66 & & GGA & 100 & 1.19 \\
\hline & GUG & 69 & 0.83 & & CAG & 22 & 0.34 & & GGG & 96 & 1.14 \\
\hline \multirow[t]{4}{*}{ Ser } & UCU & 124 & 1.90 & Asn & AAU & 125 & 1.52 & & & & \\
\hline & UCC & 28 & 0.43 & & AAC & 40 & 0.48 & & & & \\
\hline & UCA & 62 & 0.95 & Lys & AAA & 99 & 1.41 & & & & \\
\hline & UCG & 28 & 0.43 & & AAG & 41 & 0.59 & & & & \\
\hline \multirow[t]{4}{*}{ Pro } & $\mathrm{CCU}$ & 90 & 1.80 & Asp & GAU & 90 & 1.42 & & & & \\
\hline & $\mathrm{CCC}$ & 48 & 0.94 & & GAC & 37 & 0.58 & & & & \\
\hline & CCA & 45 & 0.90 & Glu & GAA & 88 & 1.09 & & & & \\
\hline & CCG & 18 & 0.36 & & GAG & 73 & 0.91 & & & & \\
\hline
\end{tabular}

Relative Synonymous Codon Usage (RSCU) is the observed frequency divided by the expected frequency under the assumption of equal usage of synonymous codons. An RSCU of 1 indicates equal usage of codons for an amino acid.

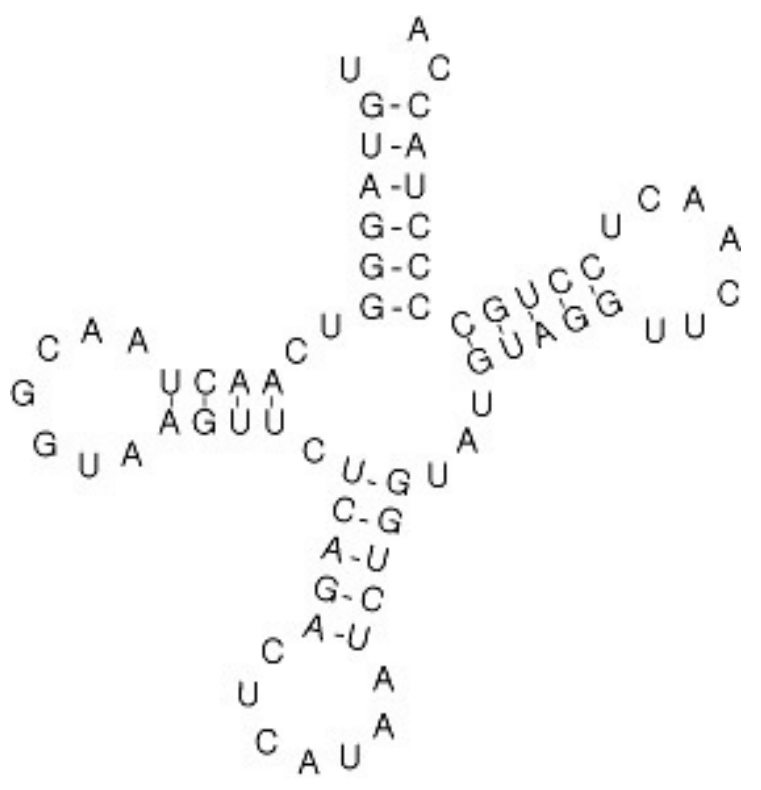

Fig. 2. The secondary structure of tRNA ${ }^{\text {Met }}$.

199 bp except between $n d 2-n d 5$ where the two genes a overlapped by $13 \mathrm{bp}$. The longest non-coding region was located between $c y t b$ and $n d 6$.

\section{DISCUSSION}

The $D$. gigantea mitochondrial genome was of $18,842 \mathrm{bp}$ in length, and comprised 14 protein coding genes, two rRNAs, and only one tRNA. In general, mitochondrial genes, such as cox 1 and $n d 2$, are widely used for phylogenetic analysis due to high substitution rates compared to those of nuclear genes (Gissi et al., 2008). However, mitochondrial genes of corals are inappropriate to reveal evolutionary relationships because of the low genetic variation and substitution rate (Hellberg, 2006; McFadden et al., 2006). Therefore, a large number of informative DNA sequences are needed to better understand octocoral phylogeny. For this reason, whole mitochondrial genomes are a good resource for phylogenetic information, including gene content and gene order as well as DNA sequences. The study using 13 protein coding genes from 17 hexacorals and 3 octocorals suggested that one of the two clades of scleractinia is closely related to the corallimorpharia than to the other clade of scleractinia hence the corallimorpharia should be included in the scleractinia (Med- 
ina et al., 2006). Our previous study including the protein coding genes from $D$. gigantea estimated the divergence time among four octocorals approximately 50-79 Ma (Kim et al., 2008). These studies contributed to better understand of the anthozoan evolution. However, the insufficient taxon sampling acts as a limit for better understanding of the evolutionary relationships and molecular evolutionary patterns of mitogenome of anthozoans. Therefore more mitochondrial genome sequencings and characterizations are needed for further study.

\section{ACKNOWLEDGEMENTS}

We thank Jun-Im Song for her species identification of $D$. gigantea. This work was supported by the Korea Research Foundation Grant (KRF-2005-070-C00124) to Y.J. Won.

\section{REFERENCES}

Anderson, S., A. Bankier, B. Barrell, M. De Bruijn, A. Coulson, J. Drouin, I. Eperon, D. Nierlich, B. Roe and F. Sanger, 1981. Sequence and organization of the human mitochondrial genome. Nature, 290(5806): 457-465.

Berntson, E., S. France and L. Mullineaux, 1999. Phylogenetic relationships within the Class Anthozoa (Phylum Cnidaria) based on nuclear 18S rDNA sequences. Mol. Phylogenet. Evol., 13(2): 417-433.

Brugler, M. and S. France, 2007. The complete mitochondrial genome of the black coral Chrysopathes formosa (Cnidaria: Anthozoa: Antipatharia) supports classification of antipatharians within the subclass Hexacorallia. Mol. Phylogenet. Evol., 42(3): 776-788.

Brugler, M. and S. France, 2008. The mitochondrial genome of a deep-sea bamboo coral (Cnidaria, Anthozoa, Octocorallia, Isididae): genome structure and putative origins of replication are not conserved among octocorals. J. Mol. Evol., 67(2): 125-136.

Daly, M., M. Brugler, P. Cartwright, A. Collins, M. Dawson, D. Fautin, S. France, C. McFadden, D. Opresko and E. Rodrigues, 2007. The phylum Cnidaria: a review of phylo- genetic patterns and diversity 300 years after Linnaeus. Zootaxa, 1668: 127-182.

Gissi, C., F. Iannelli and G. Pesole, 2008. Evolution of the mitochondrial genome of Metazoa as exemplified by comparison of congeneric species. Heredity, 101(4): 301-320.

Hellberg, M., 2006. No variation and low synonymous substitution rates in coral mtDNA despite high nuclear variation. BMC Evol. Biol., 6(1): 24.

Kim, B., S.-R. Kong, J.-I. Song and Y.-J. Won, 2008. Molecular phylogeny and divergence time estimation of the soft coral Dendronephthya gigantea (Alcyonacea: Nephtheidae). Korean J. Syst. Zool., 24, 327-332.

Librado, P. and J. Rozas, 2009. DnaSP v5: a software for comprehensive analysis of DNA polymorphism data. Bioinformatics, 25(11): 1451.

Lowe, T. and S. Eddy, 1997. tRNAscan-SE: A program for improved detection of transfer RNA genes in genomic sequence. Nucleic Acids Res., 25(5): 955.

McFadden, C., S. France, J. Sanchez and P. Alderslade, 2006. A molecular phylogenetic analysis of the Octocorallia (Cnidaria: Anthozoa) based on mitochondrial protein-coding sequences. Mol. Phylogenet. Evol., 41(3): 513-527.

McFadden, C., J. Sanchez and S. France, 2010. Molecular Phylogenetic Insights into the Evolution of Octocorallia: A Review. Integrative and Comparative Biology, doi:10.1093/ $\mathrm{icb} / \mathrm{icq} 056$.

Pont-Kingdon, G., N. Okada, J. Macfarlane, C. Beagley, C. Watkins-Sims, T. Cavalier-Smith, G. Clark-Walker and D. Wolstenholme, 1998. Mitochondrial DNA of the coral Sarcophyton glaucum contains a gene for a homologue of bacterial MutS: a possible case of gene transfer from the nucleus to the mitochondrion. J. Mol. Evol., 46(4): 419-431.

Sinniger, F., P. Chevaldonne and J. Pawlowski, 2007. Mitochondrial genome of Savalia savaglia (Cnidaria, Hexacorallia) and early metazoan phylogeny. J. Mol. Evol., 64(2): 196203.

Wang, X. and D. Lavrov, 2007. Mitochondrial genome of the homoscleromorph Oscarella carmela (Porifera, Demospongiae) reveals unexpected complexity in the common ancestor of sponges and other animals. Mol. Biol. Evol., 24(2): 363.

Received September 20, 2010 Accepted November 12, 2010 